\title{
2020 Post-Crisis Development and 2021 Trends in Russia and Europe: Fintech and Digital Assets Regulation
}

\section{凡目 Maria Agranovskaya}

Attorney at Law, Managing Partner, GRAD Legal \& Financial Advisory Services. Address: 33/2, bld. 1, Baumanskaya Str., Moscow 105005, Russian Federation. E-mail: office@ agranovskaya.com

\section{凡目 David Kitsmarishvili}

Attorney at Law, GRAD Legal \& Financial Advisory Services. Address: 33/2, bld. 1, Baumanskaya Str., Moscow 105005, Russian Federation. E-mail: kic-david@mail.ru

\section{䟚目 Abstract}

The article examines 2020 post-crisis results and 2021 trends in FinTech regulation development. FinTech companies are entering the financial market in collaboration - or competition - with classic players. These new alliances are transforming the market. Speed and cost savings have been decisive, and DeFi applications, new digital banks and the digitization of assets are rapidly evolving. Innovation needs regulatory updates to be legitimate. The most revolutionary developments have appeared in smaller European countries, which the leaders are forced to follow. Law harmonization has become a natural step forward for Europe to regulate blockchain businesses and to agree on terminology and risk prevention measures for innovation support. Talks on MiCA regulations have begun. On account of anti-laundering and terrorism prevention rules for businesses, confidentiality has virtually ceased to exist in the blockchain space, which had previously been anonymous. The commercial turnover of big data and the use of artificial intelligence in financial services have led to problems in customer protection and privacy. Technology standards are also a key area of regulation. New types of stablecoins are playing important role in technology-based markets (from Tether to the Binance USD). Libra as a potential supranational currency is awaiting regulation in Switzerland yet meeting with resistance internationally. Finally, central banks in Sweden, China, Russia and other countries are introducing digital currencies. Changes have been accelerating on account of the crisis and pandemic, as potential solutions are appearing in the regulated classic financial market. Authors address the pros and cons of technology regulation and make a comparative analysis of the leading trends.

\section{O-国 Keywords}

FinTech; financial sector regulation; banking license; blockchain; crypto; digital assets; stablecoins; DeFi; neobanks; central bank digital currencies. 
Acknowledgements: The authors are grateful to our former colleague Olga Antonova for her help and valuable comments on several parts of the article.

For citation: Agranovskaya M., Kitsmarishvili D. (2020) 2020 Post-Crisis Development and 2021 trends in Russia and Europe: Fintech and Digital Assets Regulation // Legal Issues in the Digital Age, no 3, pp. 35-58.

DOI: $10.17323 / 2713-2749.2020 .3 .35 .58$

\section{Introduction}

Despite its recent appearance, FinTech has already become a major industry that combines rapidly developing technologies (digital solutions, blockchain, artificial intelligence (AI) and machine learning, Internet of things (IoT), big data, etc.) with financial products and services. This has led to the emergence of new terms and concepts such as DeFi (decentralized finance).

The experience of the 2008 crisis is important to analyse the current 2020 situation and crisis outcomes. It helps to understand present-day issues and predict future trends. The year 2008 apparently gave rise to new FinTech projects and initiatives for the innovation and renewal of banking, insurance, payment systems, lending and other financial areas [Arner D. et al, 2020: 4].

The period 2020-2021 will be even more significant in our opinion. The world has changed, and technology solutions have become vital for financial players to survive and remain competitive.

Today, most countries are keen to regulate FinTech and support innovation. The adoption of new regulations has accelerated on account of the social and economic impacts of the financial crisis [e.g., Fenwick M., Uytsel S., Ying B. et al, 2020: 31]. The challenges of the future post-crisis FinTech industry will require even greater reorganization and re-evaluation of standard approaches on the part of regulators and legislators, as well as far-going international law harmonization and collaboration at different levels (between governments, regulators and crossborder associations such as R3 for legal initiative proposals) ${ }^{1}$.

The pandemic outburst has proven the importance of new mechanisms for technology implementation and of common international standards and rules of the game that have yet to be elaborated. In this article, we focus on several FinTech areas that could be the drivers of the post-crisis revival and on recent trends in regulation updates and related problems as well as analysing some approaches taken in Russia and other countries, including EU member states.

${ }^{1} \mathrm{R} 3$ is the Association of Business Recovery Professionals. Available at: https://www.r3.org. uk/ (accessed: 25.11.2020) 
A retrospective review of previous post-crisis measures is useful for understanding the efficiency of the new measures to be taken. A cross-jurisdictional comparative analysis should help to uncover the best solutions in specific FinTech areas and mechanisms for the general development of the economy such as sandboxes and experimental legal regimes [Allen H., 2020: 30]. Such work may assist in the unification and harmonization of international approaches and the identification of best practices and common standards for financial technology regulation that can open a new era in FinTech [Arner D. et al, 2016: 44]. While Professor Arner and his colleagues believed that the time has not yet come to move to internationally standardized regulatory approaches in FinTech, governments can no longer put off this issue today.

Russia has declared the national importance of FinTech and the digitization of the economy. The National Digital Economy Programme reflects this development priority ${ }^{2}$. Nevertheless, the nascent crisis has already had a serious impact on these plans. The state budget for new technology projects is being cut, and resources are being redistributed to healthcare and the support of the most affected businesses ${ }^{3}$. Nevertheless, there remains an acute need for upgrading the legal framework; this work is continuing and will be even more important for economic recovery - in this regard, we support the view expressed in Pulse of FinTech by KPMG [Pollari I., Ruddenklau A. et al, 2020: 8]. Compared to Russia, such European countries as Switzerland, Liechtenstein, Malta, have proven more efficient in FinTech regulation.

The regulatory and supervisory authorities in the aforementioned jurisdictions have adopted regulations providing special legal regimes and sandboxes for FinTech firms and even new FinTech licenses for legal operation. The issue of FinTech licenses and the inevitable competition between classic financial (credit) institutions and new FinTech firms will be discussed in more detail below.

Despite the current crisis, the year 2021 looks promising in the domain of understanding and regulating products and services based on distributed ledger technologies (DLT) and integrating other technological solutions into FinTech regulation.

\section{Major Trends}

The following trends should appear in 2021:

Globalization \& harmonization - the development of crypto-related regulations and laws will continue, and the number of progress-oriented countries will

2 The National Digital Economy Programme of the Russian Federation was adopted on July 4, 2019. The Programme includes the current normative regulation of the digital industry. Available at: URL: https://digital.gov.ru/ru/activity/directions/858/ (accessed: 25.11.2020)

${ }^{3}$ For more details, see, for example, Government Order no. 1006-p of April 13, 2020. Available at: URL: http://publication.pravo.gov.ru/Document/View/0001202004140032 (accessed: 25.11.2020) 
grow. This will most likely lead to the need for the harmonized regulation of the FinTech area, especially in such economic and political unions as the European Union (EU) and the Eurasian Economic Union (EAEU). On September 24, 2020, the European Commission (EC) adopted a new Digital Finance Package that will transform the European economy in the decades to come. The package aims to improve the competitiveness of the continent's FinTech sector and technologies, while mitigating risks and ensuring financial stability.

The new regulatory framework includes a novel regulation - Markets in Crypto Assets (MiCA)4. This regulation should ensure the support of innovative projects, a unified regulatory approach to different kinds of virtual assets, the regulation of specific activities within the EU, and the delineation from the regulation of securities and financial markets and electronic payments. General customer and investor protection rules should still apply.

At the same time, some proposals have been discussed in the global context. For example, the International Monetary Fund (IMF) has published several policy papers. IMF specialists agree that technology is changing the landscape of the financial sector, increasing access to financial services... and these changes have been in motion for several years, affecting nearly all countries in the world"'.

Nevertheless, the development of global policies on FinTech-related issues will not be driven by the IMF. The key role shall continue to be played by standardsetting bodies such as the Group of Seven (G7), the Group of Twenty (G20) and the Financial Stability Board (FSB). The FSB defines FinTech as technologically enabled innovation in financial services that could result in new business models, applications, processes or products with an associated material effect on financial markets and institutions and the provision of financial services ${ }^{6}$. In addition, the recommendations of FSB specialists state that different crypto assets definitely have the potential to enhance the efficiency of the provision of financial services, but may also generate risks to financial stability, particularly if they are adopted at a significant scale... while such financial stability risks are currently limited by the relatively small scale of these arrangements, this could change in the future"7. Generally, their recommendations call for regulation, supervision and oversight that would be proportional to the potential risks. These risks may relate to chal-

${ }^{4}$ Regulation of the European Parliament and of the Council on Markets in Cryptoassets (MiCA) Proposal. Available at: https://eur-lex.europa.eu/legal-content/EN/TXT/?uri=CELEX\%3A52020PC0593 (accessed: 26.11.2020)

${ }^{5}$ Sahay R., Beaton K. et al (2020) The Promise of FinTech: Financial Inclusion in the Post-COVID-19 Era. IMF Departmental Paper No. 20/09, p. 11.

${ }^{6}$ Available at: https://www.fsb.org/work-of-the-fsb/policy-development/additional-policy-areas/monitoring-of-fintech/ (accessed: 26.11.2020)

7 FSB. Final Report and High-Level Recommendations 2020 P.1. Available at: https://www. fsb.org/wp-content/uploads/P131020-3.pdf (accessed: 27.11.2020) 
lenges to financial stability; consumer and investor protection; data privacy and protection; financial integrity, including compliance with rules governing antimoney laundering and countering the financing of terrorism and proliferation (AML/CFT); tax evasion; fair competition and antitrust policy; market integrity; sound and efficient governance; cyber security and other operational risks; as well as the safety, efficiency and integrity of financial market infrastructures (FMIs) (e.g., payment systems); and resolution and recovery considerations ${ }^{8}$.

The FSB has agreed to the following actions as key building blocks of the roadmap to enhance cross-border payments commissioned by the G20:

First of all, the completion of international standard-setting work by December 2021. These standards should become guiding principles for further cooperation.

Second, the establishment or adjustment of cooperation arrangements among authorities by December 2021 (and subsequently as needed based on market evolution).

Third, at the national level, the establishment and/or adjustment of regulatory, supervisory and oversight frameworks consistent with FSB recommendations and international standards and guidance by July 2022 .

Finally, the review of implementation and the assessment of the need to refine or adapt international standards by July $2023^{9}$.

The Financial Action Task Force (FATF) has expanded the aforementioned FSB findings in the FATF report to the G20 on stablecoins. The FATF has found that crypto assets (in particular, stablecoins) share many of the same potential money laundering and terrorist financing risks as some virtual assets in virtue of their potential for anonymity, global reach and layering of illicit funds ${ }^{10}$.

\subsection{Development of Regional Regulations}

Local regulations have become a leverage and investment-promotion instrument for some countries, e.g., in the domain of blockchain. Smaller European countries have been more active and successful in improving their legal frameworks to support innovation. The introduction of new legislation for supporting innovations that trigger economic development and attract investments has become popular worldwide. Some offshore jurisdictions (such as the Cayman Is-

8 Ibid. P. 7.

9 Available at: https://www.fsb.org/work-of-the-fsb/policy-development/additional-policy-areas/monitoring-of-fintech/ (accessed: 26.11.2020)

${ }^{10}$ FATF (2020), Report to the G20 Finance Ministers and Central Bank Governors on So-called Stablecoins. P.32. Available at: https://www.fatf-gafi.org/media/fatf/documents/ recommendations/Virtual-Assets-FATF-Report-G20-So-Called-Stablecoins.pdf (accessed: 26.11.2020) 
lands, BVI, Bermuda, etc.) and post-Soviet countries have begun to regulate crypto and digital assets [Ward M. et al 2020: 39] ${ }^{11}$.

Technology development - the interest of different governments in FinTech is driven by the growing potential of technologies.

Technological giants such as Alibaba, Alphabet, Apple and Tencent focus on FinTech projects, especially in developing markets - whether directly or by forging investments. Not only Big Tech companies but even FinTech startups invest in other emerging firms in order to augment their capabilities, get access to talent more quickly, and grow. This area is interesting for governments, as it includes the development of artificial intelligence (AI) that can be used by government bodies in different sectors, including the financial domain.

In Russia, for example, the use of robots and AI in financial services (legitimate sources of information, its status, cybersecurity, know your customer/anti-money laundering (KYC/AML), algorithmic trade, the use of bots, sources of information for AI, etc.) has become the subject of regulators' attention following Presidential Decree no. 490 On the Development of Artificial Intelligence in the Russian Federation of October 10, 2019 (the AI Decree together with the National Strategy of AI Development for the Period until 2030 ${ }^{12}$. A new experimental regime was launched in Moscow in 2020 as the specific legal regime for AI-related projects. In this area, not much has been done in the domain of regulation so far, yet the latter has been clearly declared the top priority.

In addition to innovation potential, such aspects of progress as the human factor, privacy and the elaboration of standards for drones and robots should not be overlooked. Here we should note the legislative initiatives of some leading market players (Media Communication Alliance, FinTech Association), including a Data Ethics Code, which should serve as the regulatory foundation for big data. A draft version of the Unified Information Code is still being reviewed. It should systemize legislative acts in the areas of telecom and information and integrate different acts on information, information technology, data protection and other issues. An important new document has finally been enacted: Federal Law № 258-FZ On Experimental Legal Regimes in the Digital Innovation Field in the Russian Federation of August 31, 2020 ("ELR Law") that will come into force on January 28, 2021.

Digital technology projects in the financial industry should be managed by the Central Bank and may become the subject of a separate regulatory regime. This is a long-awaited act. Sandboxes and experimental regimes - banks in different jurisdictions (including Russia) are highly active in new technology implementa-

${ }^{11}$ Russia, Belarus, the Ukraine and some other post-Soviet countries are currently working on the development of FinTech regulations (e.g., the Russian Central Bank and the National Bank of Ukraine are currently developing sovereign e-currencies).

12 Available at: URL: http://www.kremlin.ru/acts/bank/44731 (accessed: 27.11.2020) 
tion and the establishment of accelerators (e.g., Sberbank, Tinkoff, VTB). As the regulator, the Central Bank of Russia (CBR) may be rather conservative, yet it is proactive as the promoter of new technologies.

The CBR launched a sandbox in April 2018 for piloting and modelling processes for new financial services and technologies in the event that regulations need amendment ${ }^{13}$. In general, such sandboxes facilitate conducting risk analysis, justifying the expediency of new projects, elaborating the required regulations (if needed), and supervising projects. To address this, the special CBR Expert Market Participants Council (including technology and financial market associations) and the Interdepartmental Expert Council (government bodies) have been established. An applicant can be any entity proposing an innovative financial project. The CBR analyses the need for implementation via its council (with additional questions and technological tests). Priority is given to digital technologies. The DLT itself and the crowdfunding platforms controlled by the CBR are welcomed by the regulator, while foreign cryptocurrency and tokens issued abroad are not. The new federal law shall be another incentive for further development.

The Swiss FINMA and Singapore MAS precedents of creating new legitimate grounds and attracting investments by reviewing projects on a case-by-case basis could be much more successful for Russia than lengthy vertically governed legislative processes and their subsequent implementation, especially in view of rapidly changing technologies. The CBR is not highly active in Russia compared to regulators in Switzerland, Liechtenstein, Singapore, Malta and other countries.

Taxation of crypto assets - besides the development of AI and experimental regimes for FinTech companies, states are also interested in controlling and taxing crypto assets and crypto-related activities such as mining, payment systems, etc.

The Russian Ministry of Finance has proposed draft amendments of the Federal Tax Code for the declaration of crypto assets, yet they are far from ideal, and the understanding of the technological aspects of digital assets remains low at the level of implementing officials. Certain innovation-related tax benefits are also being discussed.

FinTech \& blockchain licenses- some countries have implemented digital banking and FinTech licenses to stimulate competition and deliver services to under-served/un-served segments of the population and to support innovation. New FinTech firms and digital neobanks may now be regulated by more appropriate legislation without the burdensome rules for traditional banks. For more information on FinTech licenses, see Neobanks. New FinTech and Blockchain-Related Licenses below.

Decentralized financing (DeFi) - new decentralized applications in place of traditional financial service providers are rapidly occupying a substantial market

\footnotetext{
${ }^{13}$ Available at: http://old.cbr.ru/eng/fintech/regulatory-sandbox/ (accessed: 27.11.2020)
} 
niche. The new technologies help to reduce transaction costs, facilitate the integration of decentralized platforms with each other, produce distributed trust with no single failure point, and reduce costs by the elimination of mediators. The new business models are highly competitive. Decentralized financial services may become even more decentralized, innovative, interoperable, borderless, and transparent [Chen Y., Bellavitis C., 2019: 27]; [Zetzsche D. et al 2020: 56]. Centralized DeFi players are more reliable in comparison to decentralized ones, and so the combination of efforts with regulated players allows the segment to access institutional players and become accepted. DeFi is attracting the attention of central banks and the leaders of classic finance industry. DeFi approaches are also taken into account by regulators for the sovereign issue of digital currencies that have become a hot trend in 2020 .

The first steps have already been taken. On October 9, 2020, the Bank of International Settlements (BIS) together with seven central banks of different countries published the first central bank digital currency (CBDC) report laying out the key requirements ${ }^{14}$.

The BIS Report outlines the foundation principles and core features of a CBDC. About $10 \%$ of leading central banks are ready to introduce their own digital hard currencies to replace cash.

Although many legal issues must still be cleared, the idea is already being put into practice in pilot programs in such states as Sweden and China, while Russia's Central Bank has published a report and announced public consultations ${ }^{15}$.

Institutional players and regulated crypto services - alliances and partnerships will accelerate between Big Tech players and FinTech-oriented firms, traditional corporations and startups and even between the FinTech firms themselves; moreover, these partnerships will be highly regulated and customer-oriented. The unpacking of financial products will lose popularity as consumers increasingly seek a solution to complex and fragmented digital issues, preferring a trusted platform over an unknown application. PayPal is partnering with PAXOS to allow its clients to buy crypto (yet not to sell or trade it). Binance is issuing BUSD with NYDFS and PAXOS - its first regulated stablecoin ${ }^{16}$.

Collaboration or competition: classic financial institutions and FinTech firms - FinTech firms and challenger banks will continue to expand the range of their service offerings beyond their initial niche area. The focus on open data

${ }_{14}$ The BIS Report was drafted together with the European Central Bank, the central banks of Canada, Japan, Sweden, Switzerland, and the United Kingdom, and the US Federal Reserve. For more details, see the official BIS webpage. Available at: https://www.bis.org/press/p201009. htm. (accessed: 28.11.2020)

15 Available at: http://cbr.ru/analytics/d_ok/dig_ruble/ (accessed: 28.11.2020)

16 Available at: https://www.paxos.com/busd/ (accessed: 28.11.2020) 
opportunities will move beyond banking into other aspects of the financial service industry as well as solving common difficulties in other sectors such as power, telecommunications, etc. Deals based on FinTech will predictably be seen in jurisdictions outside of traditional markets, such as Southeast Asia, Latin America and Africa.

Confidentiality or transparency, preventing money laundering and terrorism financing vs. protecting privacy - anonymity in finances is almost non-existent, including the crypto space when it comes in touch with classic finance.

In the following sections, we will discuss in greater detail the impact of FinTech on payments, the traditional banking system, and the regulation of the financial sector as well.

\subsection{Neobanks. New FinTech and Blockchain-Related Licenses}

Payments are essential for the proper functioning of the economy. McKinsey estimates that global payment revenues totalled \$1.9 trillion in 2018 and continued to grow in 2019 [Bruno P. et al, 2019: 2]. While banks have traditionally dominated the payments market, they are currently facing intense competition from FinTech firms, on the one hand, and sovereign states, on the other [Panzarino H. et al, 2020: 10]. In the United States, for example, technology giants such as Google, Facebook, and Microsoft have already entered the payments market. In China, mobile payments for consumption alone account for about $16 \%$ of the $\mathrm{GDP}^{17}$. In addition, regulations such as the Revised Directive on Payment Services (PSD 2) ${ }^{18}$ in Europe or the Services Regulations $2017^{19}$ in the UK have spurred FinTech to enter the sphere of payment services.

Sovereign states are also contemplating introducing digital currencies of their own. In the US, a digital dollar has been introduced three times in different bills [Hockett R., 2020: 7]. Previous bills of March 2020 suggested distributing immediate digital cash relief for recovery from COVID-19, but this was not approved. Instead, the aforementioned acts have proposed that digital dollar wallets should become available by the start of 2021 . The bill calls for a universal basic income of

17 BIS Annual Economic Report (2019) Big tech in finance: opportunities and risks". P. 58. Available at: https://www.bis.org/publ/arpdf/ar2019e3.pdf (accessed: 01.12.2020)

18 The PSD 2 requires banks to provide customers' account information, upon their consent, to third-party payment providers in a standardized form. For more details, see the European Commission webpage: https://ec.europa.eu/info/law/payment-services-psd-2-directive-eu-2015-2366_en (accessed: 01.12.2020)

19 By adopting the Services Regulations 2017, the UK implemented the Second Electronic Money Directive and the PSD 2. Available at: http://www.legislation.gov.uk/uksi/2017/752/ contents/made. (accessed: 01.12.2020) 
$\$ 2,000$ per month for all US citizens during the crisis and, after that, $\$ 1,000$ per month for a year.

This should be financed by the issue of $\$ 2$ trillion in dollar coins" 20 . Some other countries (BRICS member states, Venezuela, etc.) have also considered introducing national digital currencies [Kakushadze Z., Liew J., 2018: 4-5]. The Russian Parliament is also discussing the amendment of legislation on cryptocurrencies. On July 31, 2020, the Russian President signed a law on digital financial assets and digital currency, including amendments to certain acts (DFA Law).

Russian financial regulators have been hard at work reviewing a newly revised version of the DFA Law that would not criminalize Bitcoin or other cryptocurrencies. However, it is safe to say that the regulations on cryptocurrencies were imposed. These regulations will be discussed in more detail below.

After the financial crisis of 2008, banks were also forced to comply with Basel III $^{21}$, the Dodd-Frank Act ${ }^{22}$, and other similar requirements, which led to increasing costs. In response to the aforementioned competition, banks are proposing different online services to their customers and trying to reduce high operational expenses for employee salaries, the lease of office space, etc. Another issue is that classic credit institutions cannot compete with startups. Slow regulatory changes and huge institutional players with internal procedures and rules are unable to regulate a promptly changing area with a lot of relatively small players. This has been an obstacle to the development and investment funding of technology and FinTech startups.

From an industry and regulatory perspective alike, one needs to take a new approach towards FinTech regulation. From this point of view, the examples of Switzerland, the UK, Liechtenstein, Gibraltar, and Malta are particularly interesting.

Singapore, known as the Asian Switzerland", is another world leader that has done a lot for harmonizing its financial regulations with Western Europe. However, a detailed analysis of its legal novelties shall be the subject of an another article (upcoming).

Gibraltar was the first jurisdiction to implement special FinTech regulatory legislation. By passing the Financial Services (Distributed Ledger Technology or DLT) Regulations $2017^{23}$ that entered into force on January 1, 2018, the Gibraltar

${ }^{20}$ Available at: https://tlaib.house.gov/sites/tlaib.house.gov/files/ABCAct.pdf.(accessed: 01.12.2020). The bill was introduced on April 16, 2020.

${ }^{21}$ Basel III is a global regulatory framework on bank capital adequacy, liquidity risks, and stress testing. Available at: https://www.bis.org/bcbs/basel3.htm. (accessed: 01.12.2020)

22 The Dodd-Frank Act is an integrated bill that put strict regulations on the US financial industry and created programs to stop mortgage companies and lenders from taking advantage of consumers.

${ }^{23}$ Available at: http://www.gfsc.gi/uploads/DLT\%20regulations\%20121017\%20(2).pdf. (accessed: 01.12.2020) 
Financial Services Commission (GFSC) became the standard-setting body licensing any person (legal entity), in or from Gibraltar, that uses DLT for storing or transmitting value belonging to others.

Liechtenstein was also among the world's first jurisdictions to pass a specialized Blockchain Act" ${ }^{24}$. The Blockchain Act applies to all trustworthy technologies service providers (instead of blockchain or distributed ledger technology", the term trustworthy technology or TT is used). From January 1, 2020, the following professional service providers in Liechtenstein must register with the Financial Market Authority of Liechtenstein (FMA):

Token issuers - entities publicly offering tokens ${ }^{25}$ on behalf of third parties (e.g., a trading venue carrying out an ICO). Furthermore, persons making a private placement must also register if the value of the tokens sold in one year exceeds or shall exceed CHF 5 million.

Token generators - entities generating original tokens on behalf of third parties.

TT Key Depositaries and TT Token Depositaries — entities that safeguard tokens or private keys for third parties, e.g., in a safe or a collective wallet. This also includes the execution of transactions for third parties. These services are typically provided by crypto exchanges (such as Bittrex) and wallet providers.

Generally speaking, the law clearly specifies all the service providers that should be registered (licensed) by the Liechtenstein FMA. In addition to the aforementioned providers, they include TT Protectors and Physical Validators, TT Exchange Service Providers, TT Verifying Authorities, as well as TT Price and Identity Service Providers ${ }^{26}$. The Blockchain Act aims to improve investor protection, combat money laundering and establish legal certainty in regulating blockchain projects.

The Maltese legal framework governing the FinTech industry includes three main laws: the Innovative Technology Arrangements and Services Act (ITAS), the Malta Digital Innovation Authority Act (MDIA), and the Virtual Financial Assets Act (VFAA), supplemented by guidance of the Malta Financial Services Authority.

Licensing issues are regulated by the VFAA. One of the salient features determining the applicability of the VFAA is the type of asset with which the operator deals. Through the application of the Financial Instrument Test, a DLT asset (i.e.,

${ }^{24}$ Originally, the Token and TT-Service Provider Act (the so-called Blockchain Act") was adopted by the Liechtenstein Parliament on October 3, 2019, and entered into force on January 1, 2020. Available at: https://www.regierung.li/media/medienarchiv/950_6_04_11_2019_ TVTG_english.pdf?t=1 (accessed: 01.12.2020)

${ }^{25}$ In the Blockchain Act (art. 2), a token stands for a piece of information on a TT System (i.e., blockchain) and for a kind of container for representing a right.

${ }^{26}$ For more details, see Liechtenstein's FMA. Available at: https://www.fma-li.li/en/fintechand-tvtg.html (accessed: 02.12.2020) 
a cryptocurrency) is classified as a virtual token, a financial instrument, e-money or a virtual financial asset in accordance with the VFAA. It should be said that EU directives and regulations on markets of financial instruments, e-money, and payment services, as well as anti-money laundering laws, are additionally applicable. The same holds for Gibraltar, as we mentioned earlier. The provision of the following services in or from within Malta in relation to a DLT asset which has been determined to be a virtual financial asset in terms of VFAA, requires a license:

Reception \& transmission of orders: the reception from an entity of an order to buy, sell or subscribe to virtual financial assets and the transmission of that order to a third party for execution.

Execution of orders on behalf of other persons: concluding agreements on buying, selling or subscribing to one or more virtual financial assets on behalf of another entity.

Custody or nominee services: acting as a custodian or nominee holder of a virtual financial asset and/or private cryptographic key or holding a virtual financial asset and/or private cryptographic key as a nominee, where the entity acting as the nominee is doing so on behalf of another entity.

Portfolio management: managing assets (one or more virtual financial assets or arrangements) belonging to another entity with the discretion to invest any of these assets in one or more virtual financial assets.

Dealing on one's own account: trading against proprietary capital resulting in the conclusion of transactions involving one or more virtual financial assets.

Investment advice: giving, proposing or agreeing to give personal recommendations with regard to one or more transactions relating to one or more virtual financial assets to entities in their capacity as investors or potential investors or as an agent for an investor or potential investor.

Placement of virtual financial assets: marketing newly issued virtual financial assets or virtual financial assets which are already issued yet not admitted to trading on a DLT exchange to specific entities without making an offer to the public or to existing holders of the issuer's virtual financial assets.

Operations of a VFA exchange: virtual financial assets may be exchanged, which requires specific regulations.

In order to provide the above services, one needs to obtain a license. There are four types of FinTech licenses. VFAA Class 1: license holders are authorized to receive and transmit orders and/or provide investment advice in relation to one or more virtual financial assets and/or place virtual financial assets. Class 1 license holders are not authorized to hold or control clients' money or assets. VFAA Class 2: license holders are authorized to provide all VFA services and to hold or control clients' money yet not to operate as a VFA exchange or deal on their own. VFAA Class 3: license holders are authorized to provide all VFA services and to hold or control clients' money yet not to operate as a VFA exchange. VFAA Class 4: 
license holders are authorized to operate as a VFA exchange, to hold or control clients' money, virtual financial assets and private cryptographic keys, and to provide custodian or nominee services solely in relation to the operation and activities of such a VFA exchange.

The Virtual Financial Assets Act sets down the application procedure and the requirements that the service providers must meet in order to receive a license, including, but not limited to, organizational requirements, financial requirements, operational requirements, and requirements relating to anti-money laundering (AML), combating the financing of terrorism (CFT), and cybersecurity ${ }^{27}$.

The VFAA license only covers services relating to virtual financial assets. If an asset is classified as a financial instrument, then any services provided in relation thereto (including placement) would require prior authorization under the traditional financial services legislation.

The Swiss legal framework governing the activities of traditional banking (financial) services and FinTech firms consists of federal acts, implementing executive orders and a number of circulars, as well as guidance of the Financial Market Supervisory Authority (FINMA). In addition, a new FinTech license has been introduced by the recent amendments to the Banking Act 201928. FinTech-related companies came into conflict with the Banking Act, as the acceptance of deposits from the public requires a banking license. As the Banking Act sets down stringent conditions for granting licenses, the banking license serves as a considerable barrier for FinTech companies that want to enter the market.

The current Swiss FinTech model provides opportunities for all market participants, whether established financial service providers or startup companies. FINMA takes an intrinsically neutral stance towards new business models and technologies and considers innovation as an important factor for the competitiveness of the Swiss financial market. At the same time, the Swiss standard-setter pays close attention to prudential and conduct supervision ${ }^{29}$. FINMA only supervises institutions it has authorized to engage in financial market activity. This supervisory function is prudential with respect to banks, insurance companies and other financial service providers: these institutions must always have adequate capital buffers and liquidity and should have their risk exposure under control.

Switzerland's model is based on the following core elements: a FinTech license allows non-bank companies to accept deposits from the public without conduct-

${ }_{27}$ Available at: https://www.mfsa.mt/fintech/virtual-financial-assets/\#legislativeRegulatoryFramework. (accessed: 02.12.2020)

${ }_{28}$ Available at: https://www.admin.ch/opc/de/classified-compilation/19340083/index.html. (accessed: 02.12.2020)

${ }_{29}$ FINMA Annual Report 2019. Available at: https://www.finma.ch/en/search/ (accessed: $02.12 .2020)$ 
ing any lending operations with maturity transformation or interest payments (Art. $1 \mathrm{~b}$ of the Banking Act 2019); the conditions to be fulfilled for obtaining a FinTech license are less stringent than for traditional banks: deposits may not exceed the value of CHF 100 million and may not be reinvested; the minimum capital shall always be three percent of the total amount of deposits held yet not less than CHF 300,000; a legal entity pursuant to Art. 1b of the Banking Act 2019 is subject to supervision by FINMA.

The aforementioned requirements allow FinTech firms to appear and compete with classic banks. As of October 26, 2020, there exists a registered entity licensed by FINMA pursuant to Art. 1b of the Banking Act 201930: Yapeal AG, a neobank registered in Zurich ${ }^{31}$. Yapeal will offer accounts with Swiss IBAN without being tied to an offline bank payment system. Having both FINMA banking and securities dealer licenses, Sygnum and SEBA ${ }^{32}$ banks also provide examples of how traditional and innovative banking services can be combined. These crypto banks enable professional individuals and companies as well as institutional clients to invest, safekeep, trade, and borrow against digital and traditional assets, all in one space. For Swiss blockchain companies, these banks provide accounts and custody for fiat and digital assets. In addition, they intend to issue their own digital currencies (Sygnum, for example).

The Russian FinTech market has been growing significantly over the past two years in terms of both the number of transactions and the volume of investments. The market has several particularities: Russia is a leading global supplier of IT specialists, and some areas such as $\mathrm{P} 2 \mathrm{P}$ lending, crowd investments and cryptocurrencies have yet to be regulated. According to some FinTech companies, the key challenges facing the Russian market include the low interest of external investors, the low spending power of citizens, geopolitical risk and the inflexibility of the taxation system.

In 2018, as we mentioned above, the Russian Central Bank created a regulatory sandbox to encourage the development of new financial services and technologies such as a system of fast payments, a unified system of biometric identification, and a financial supermarket.

Accelerators such as the FRII accelerator and the HSE incubator regularly support the development of FinTech startups. FinTech partnership programs designed to help early-stage startups to meet market needs were set up back in 2018 by Sberbank, Raiffeisenbank, Tinkoff and Alfa Bank. Several banks also acquired startups in the field of loyalty and payments, including Alfa Bank (Cardsmobile)

${ }^{30}$ The list of persons licensed by FINMA. Available at:: https://www.finma.ch/en/search/. (accessed: 03.12.2020)

31 Available at:: https://yapeal.ch/\#intro. (accessed: 03.12.2020)

32 Available at:: https://www.seba.swiss/ (accessed: 03.12.2020) 
and Tinkoff (Cloudpayments). The UK FinTech unicorn Revolut also entered Russia in 2018 via a licensing deal with Qiwi Bank. Russia's Central Bank has launched a FinTech association and a sandbox designed to support further development.

The FinoPolis FinTech forum is also strengthening the ecosystem. Cryptocurrencies and tokens are legal yet discouraged means of payment while ICOs and crowdfunding have gained popularity as alternative sources of capital. Accelerators and incubators such as Russia FinTech Lab, Huobi, Digital Horizon and Digital October are active in the country, as are over $70 \mathrm{VC}$ firms, which invested a total of over 212 million euros in 2017.

\section{Blockchain Assets: New Forms}

The past years have witnessed the emergence and development of the main approaches to the classification and legal qualification of digital and blockchainbased assets. Grounded in classical legal theory, new relations and forms of asset transfer have led to changes in the terminological framework. Indeed, this was the most difficult aspect of all. What is cryptocurrency? How shall it be accounted for? As money, goods, derivatives or a programme code protected by intellectual property provisions?

The clear definition and classification of blockchain-based assets is an essential condition for their proper regulation by the legal system; this is particularly important in the context of the highly regulated financial sector and DLT-based crowdfunding. The initial understanding of the term and its applications has changed not only in theoretical works but also in the practice of regulatory and supervisory bodies in different jurisdictions. We should note that the terms smart properties and smart contracts were already used by [Szabo N., 1994], which described peerto-peer finance operations where all participants are equal (also casting the foundations for DeFi as we know it today) and specified that software should fully embed the contractual terms relating to property in the property itself. In 1998, the concept was further developed in B-money by Wei Dain, who wrote about an independent protocol whose execution would be triggered by a public cryptographic key ${ }^{33}$.

Without a doubt, the first cryptocurrency that most people heard about was Bitcoin. Bitcoin is basically the modern version of the smart contract (just as Side Chains, NXT, Ethereum and some other cryptocurrencies) [Savelyev A. 2016: 7-10]. Bitcoins and smart contracts have certain similar features and operating principles. Apart from being a code that may be protected by intellectual property laws, Bitcoin is a separate value item per se that can be transferred freely, anonymously and without mediators. Some other new digital asset types not only

${ }^{33}$ Available at:: http://www.weidai.com/bmoney.txt. (accessed: 03.12.2020) 
include unique codes but also play a role in the system, have additional functions and/or are derivatives from real assets. Many different types of new assets have appeared, and they continue to develop today.

Japan was among the first to acknowledge Bitcoin as legal tender by a special act in 2017. To keep up to date with recent progress and market changes, a new act entered into force this year as a revision of the Act on Settlement of Funds and the Financial Instruments and Exchange Act, and crypto-related regulations have been tightened. Apart from the new requirements on margin trading, crypto derivatives, risk transparency and hack prevention, the term virtual currencies has been replaced by crypto assets".

Switzerland has been among the leaders in theory elaboration and regulatory development. The first ICO Guidance, issued in September 2017, acknowledged the impossibility of catch-all definitions. A separate warning noted that real cryptocurrencies should be stored on distributed networks and use blockchain technology"34. Extensive FINMA documents have been published, and the doctrine has been supported with high-quality materials, including articles by the MME Law Firm on the nature and legal essence of cryptocurrencies and tokenized assets.

The small territory of Gibraltar was the first to adopt advanced DLT-related regulations. In early 2014, a private cryptocurrency working group was launched to examine crypto matters; in early 2016, the Gibraltar government began to collaborate with it, and a discussion paper was issued ${ }^{35}$. Distributed ledger technology is defined in the Financial Services (Investment and Fiduciary Services) Act of $1989^{36}$ as a database system in which (a) information is recorded and consensually shared and synchronized across a network of multiple nodes and (b) all copies of the database are regarded as equally authentic. 'Value' includes assets, holdings and other forms of ownership, rights or interests, with or without related information, such as agreements and transactions for the transfer of value or its payment, clearing or settlement." This approach was subsequently adopted by some others: defining not cryptocurrency but the technology and its manifestations and the ways how assets are used and issued. On October 12, 2017, the Financial Services (Distributed Ledger Technology Providers) Regulations 2017 were made public in accordance with the Financial Services (Investment and Fiduciary Services) Act. These regulations entered into force on January 1,2018. Their most important effect was to convince organizations that it is good to be regulated. The rules have allowed persons who are willing to be regulated and who have stable grounds for

${ }_{34}$ FINMA Report 2017. Available at: https://www.finma.ch/en/news/2017/09/20170919mm-coin-anbieter/ (accessed: 03.12.2020)

35 Available at: http://www.fsc.gi/uploads/GoGPR12102017.pdf (accessed: 03.12.2020)

${ }^{36}$ Available at: http://www.gibraltarlaws.gov.gi/articles/1989-47o.pdf(accessed: 03.12.2020) 
operation to get a special license. Crypto-related financial operations could now be licensed just as classic financial services. A local regulated crypto-exchange has been launched (Global Blockchain Exchange or GBX).

Malta and other countries have followed in the wake, developing their own internal legislations. It is important to emphasize that local crypto-related legislation does not apply to business development and active marketing in other countries: what is legal in one country may still be prohibited in another. This presents difficulties, in particular, for EU member states: to adopt new blockchain-related rules, they must ensure compliance with existing local laws as well as following EU directives and regulations on financial services (MIFID II), the issue of securities (Prospectus Directive), collective investment schemes (Alternative Investment Funds Directive) and other issues.

Liechtenstein's new set of rules and the comments of the Financial Markets Authority (FMA) emphasize that cryptocurrencies are private and purely virtual currencies that are usually implemented using a blockchain. Up to now, neither the production nor the use of virtual currencies as means of payment has been subject to any licensing requirements governed by specialized legislation. In individual cases, however, there may be a licensing requirement depending on the specific type of business model ${ }^{37}$. According to the Fact Sheet on Virtual Currencies, the latter may be commonly defined as the digital representation of a (quasi-monetary) value that is issued neither by a central bank nor by any other official authority. Obviously, they are not official currencies despite the existence of certain similarities. Risks embodied in such virtual assets are addressed by the corresponding Fact Sheet and the new legislation. Bitcoin is produced by end users themselves in a decentralized fashion using special software on a computer network. Individual Bitcoins are saved in a digital wallet and can be used as a means of payment... Every transaction carried out in Bitcoin is recorded in a centralized location on the internet (a blockchain) and is thus in principle traceable. As a rule, however, the end user remains anonymous. This extended definition reflects a change in the regulators' understanding as compared to the first official publications. Digital has replaced crypto".

The new CFA Law in Russia, entered into force on January 1, 2021, defines a digital currency as electronic data (a digital code or denomination) in an information system that are offered and/or accepted as a means of payment while not being a monetary unit of the Russian Federation, a monetary unit of a foreign country and/or an international monetary or accounting unit and/or serve as an investment, and there is no person obliged to any holder of such electronic data as such, except for the operator and/or nodes of the information system that are

${ }_{37}$ Available at: https://www.fma-li.li/en/financial-centre/fintech-in-liechtenstein/business-models.html (accessed: 03.12.2020) 
responsible for assuring compliance with the information system rules on the issue of electronic data and performing actions for their entry into the information system or the amendment of entries" ${ }^{\prime 3}$. This definition is technically imperfect and uses the term information system that can generally refer to almost any database. Any bonus, electronic certificate or air miles may easily be qualified as digital currencies in the current version of the law. Previous court and supervisory practice has been very diverse and does not help to clarify the situation, either. Bitcoin and other cryptocurrencies are widely recognized as property, making it possible to protect owners' rights and use classic vindication, inheritance or transfer by contracts.

Most countries do not consider cryptocurrencies to be money", securities or commodities (with some exceptions). However, legal definitions of cryptocurrencies (as opposed to tokens, securities, money, electronic bonuses and their regimes) are often lacking. Given the transborder character of the technology, the harmonization of internationally recognized definitions and rules is essential for sector development. We are referring to upcoming major developments in this area. The most advanced example today is EU cooperation, yet it is not easy to agree upon a common set of rules for addressing such a disputable class of assets and their concomitant risks.

\subsection{Tokens and Digital Assets}

It would be important to address the key definitions and classification approaches to analysing regulation changes and key trends of the year 2020 that should continue in 2021. The pandemic has served as an accelerator of regulatory development in this area. Innovative digital models offering cost savings and mediator-free solutions are rapidly expanding on the financial market. This expansion requires supervisory bodies to pay attention to legitimate integration and collaboration with classic institutional players. The most advanced regulation of token classifications and of the rules relating to their issue and operations is found in Switzerland. Following the 2017 Guidance, FINMA published the ICO assets classification for added clarity in February 2018, stressing that there is no consistent doctrine or internationally recognized legal concept of cryptocurrency. FINMA categorises tokens into three main types (hybrid forms are also possible):

Payment tokens are synonymous with cryptocurrencies and have no further functions or links to other development projects. In some cases, tokens expand their functionality over time and become accepted means of payment;

Utility tokens are tokens that provide digital access to an application or service;

Asset tokens represent assets such as participation in real physical undertakings, companies or income streams or as entitlements to dividends or interest

${ }^{38} C f$. Clause 1, Subclause 3, of the DFA Act. 
payments. In terms of economic function, asset tokens are analogous to equities, bonds and derivatives.

The classification of tokens and its legal consequences (including forms of transactions, taxation, etc.) depend on the economic function and purpose of tokens (i.e., blockchain-based units). Another important qualifying feature is tradability or transferability. A similar approach has been taken by most regulators, including FMA, FCA (UK) and others. The principal digital classifications of assets aimed to distinguish them from securities and electronic money, yet this may be no longer sufficient today.

For example, according to Swiss specialists, the absence of a precise classification leads to some degree of legal uncertainty in practice. Moreover, the qualification of tokens for decentralized, open-sourced and community-based projects, which do not need a centralized issuer, seems to be out of the scope of the FINMA model"39. They classify tokens on the basis of functionality, target use and the existence and type of counterparty as well as the presence of an underlying asset or value. This classification includes three kinds of tokens:

Native Utility Tokens are transferred on a decentralized ledger between users; they do not give rights to another person or provide for any right except for the right relating to the token itself (issuer or transferor).

Counterparty Token represent any relative right against a third party; such tokens give the right to receive services, assets, or corporate rights.

Ownership Tokens give technical ownership rights in assets. Their purpose is to transfer rights to assets associated with the token. They refer to IP rights and material objects; they award no claims or relative rights against a counterparty but only absolute rights (erga omnes) in the form of a right in rem of the associated assets.

In terms of obligations law, it was important to decide whether tokens result in any obligations on the part of the issuer (e.g., asset-backed tokens). This also determines whether a specific asset class is transferrable by a smart contract ${ }^{40}$. A code succession or algorithm may not be sufficient to comply with the existing formalities to render a transaction valid.

This is especially problematic for internationally executed contracts for digital assets transfer. In addition, not all objects may be digitalized and transferred in a purely electronic fashion, although almost everything today can have a digital Gemini or shadow in theory. It has been noted at the World Economic Forum that, by 2027 , around $10 \%$ of the world's GDP will stem from blockchain-based contracts ${ }^{41}$.

39 Available at: https://www.mme.ch/de/magazin/bcp_framework_for_assessment_of_ crypto_tokens/ (accessed: 04.12.2020)

${ }^{40}$ Cf. FINMA Report 2018, p. 30. Available at:: https://finma.ch/de/dokumente/ (accessed: 04.12.2020)

${ }^{41}$ Available at: https://www.weforum.org/reports/how-to-end-a-decade-of-lost-productivity-growth (accessed: 04.12.2020) 
Another issue that may hinder the qualification and transfer of digital assets (for DeFi services, international ICOs or any other digital asset-related operation) is the absence of international and often even domestic standards and norms for the security level, software development quality, and use of cryptography (yet the latter may, in contrast, be highly regulated). This is important for the use of technologies by government bodies and the control of operations. Ethereum used to be the market leader, yet new technologies are currently supplanting it (e.g., Solidity, Fift (TON) and others) ${ }^{42}$.

\subsection{Stablecoins}

The initial excitement about coins and tokens and the interest in digitizing assets was naturally fuelled by the seemingly easy access to substantial amounts of funds that could allegedly be raised out of existing regulations and control. Many entrepreneurs have tried to follow this path. Initially, this was mostly the domain of IT startups. Today, such industrial giants as Norilsk Nickel are considering asset digitization and regulated stablecoin issue. Stablecoins may be a solution to increasing liquidity or accessing new markets or groups of investors, which is becoming increasingly important nowadays.

For crypto markets, stablecoins are introducing stability and means of exchange that are reliable and accepted by all market participants.

The existence of real assets behind stablecoins is not always guaranteed, as this matter is not regulated. Nevertheless, the issue of such digital assets is one of the most actively developing trends today. The Tether cryptocurrency linked to the USD is well known and widely accepted.

In September 2020, a new asset was placed on the market by Binance, a leading regulated crypto-exchange, under the supervision of New York Department of Financial Services (NYDFS). This dollar-backed stablecoin is approved by the US regulator and issued by Binance's regulated partner PAXOS, as we mentioned above. The major public auditor Withum is supporting the currency. The issue size is $\$ 209$ million, and the monthly trading volume exceeds $\$ 1$ billion. This digital dollar is bought and sold 24/7, assuring rapid and inexpensive value transfers to any part of the world with guaranteed validation. Its fixed rate is 1:1. Such instruments are introducing new operating possibilities for the financial system and competing with banking services.

A different stablecoin was announced by Libra Association linked to Facebook. The disputes around this potential supra-national competitor to national currencies have been acute, and the issue's future is not fully clear yet. France and the US

${ }^{42}$ Available at: https://mining-cryptocurrency.ru/yazyki-programmirovaniya-dlya-blokchejna-i-smart-kontraktov/ (accessed: 04.12.2020) 
are among the harshest critics of the project. The international resistance has been so serious that most institutional players (including Visa, Mastercard, and PayPal) have had to leave the association so as not to risk their licenses and positions. The Libra case has got a lot of political attention due to the enormous number of Facebook users. Switzerland has issued a detailed and well-grounded statement about Libra. In its press release of September 11, 201943, FINMA confirmed that the Libra Association had asked FINMA for an assessment of how it would classify the project in regulatory terms under Swiss supervisory law. FINMA wrote that a project of this kind would fall under financial market infrastructure regulations and only require a payment system license in accordance with the Financial Market Infrastructure Act (FinMIA) ${ }^{44}$ in addition to meeting some extra requirements.

Regulatory requirements for payment systems in Switzerland are based on prevailing international standards, particularly the Principles for Financial Market Infrastructures (PFMI). Libra has filed for a license in Switzerland and established its headquarters in Geneva.

FINMA also stated in its press release that the international scope of the project required an internationally coordinated approach and that work on elaborating requirements (in particular, for combating money laundering) should be carried out internationally, too. FINMA stressed that the project's size and scale may result in additional requirements, including even a banking license. Capital allocation, reserves, risk management, liquidity and other requirements should be calculated for the Libra project based on its business plan and submitted to FINMA. Swiss blockchain experts have emphasized that existing AML, KYC and transparency requirements will be applied and that scrutiny will be particularly close given the importance of the project. In addition, FINMA has introduced a completely new stablecoin manual that applies to other players as well ${ }^{45}$. The manual was subsequently further extended by a Supplement to the ICO Guidelines ${ }^{46}$.

In this domain, Russia has introduced the long-debated DFA Act, as we mentioned above. Its asset qualification is not exactly the same as described above: the Central Bank of Russia refuses to accept the use of any digital currency as a means of payment and stipulates that the Russian rouble remains the only means of this kind today [Yankovsky R.M., 2020: 3-4].

${ }^{43}$ Available at: https://finma.ch/en/news/2019/09/20190911-mm-stable-coins/ (accessed: 04.12.2020)

${ }_{44}$ Available at: https://www.admin.ch/opc/en/classified-compilation/20141779/index. html (accessed: 04.12.2020)

${ }_{45}$ Available at: https://www.mme.ch/de/magazin/finma_aeussert_sich_zu_libra/(accessed: 04.12.2020)

46 Available at: https://finma.ch/en/documentation/dossier/dossier-fintech/innovation-und-aufsicht-2019/ (accessed: 04.12.2020) 
The CBR has recently launched the Digital Rouble project and published a report for public consultations. Bitcoins and other privately issued cryptocurrencies are not allowed to circulate freely. A draft version of the Digital Currencies Act along with amendments to the Criminal and Administrative Codes have been presented yet have not passed the first reading so far. The Ministry of Finance has also proposed amendments to the current legislation and the Russian Tax Code, yet this has not resulted in any further action so far. In contrast to digital currencies, DFAs are digital rights that include monetary claims, rights to issued securities, non-public joint stock company capital participation rights, and the right to claim the transfer of issued securities according to the DFA conflict resolution protocol as stipulated in the Act, providing that the issue, accounting, and turnover of such assets are possible only by their entry into an information system on the basis of a distributed ledger and other information systems ${ }^{47}$. The Central Bank will undoubtedly have to issue a series of documents to clarify the numerous questions resulting from such a definition. It is currently discussing a draft document about the right of qualified (accredited) investors to buy DFAs and about the limitations on Russian investors. The DFA Act has introduced new types of regulated players (DFA issuers and exchanges). Certain classic financial market license holders will also be allowed to act as such.

Other digital assets resembling utility tokens ("utility digital rights") are regulated by the Crowdfunding Law" 48 . They do not conform to the common European understanding of utility tokens referred to above. It should be said that Russia has chosen a regulatory approach that focuses on limiting rather than developing the market, while other countries are allowing innovative projects to enter the market on the condition of risk control, mitigation and transparency.

International harmonization is extremely important. New crypto-specific regulation called MiCA (Markets in Crypto Assets) is currently being elaborated. It will address most, if not all, crypto market regulations, except for money laundering that lies outside the MIFID II and Payments Directive. While it is difficult to believe that these rules will come into force within a year, all participants are aiming at the rapid adoption of the new standards.

\section{Conclusion}

The pandemic has served as an accelerator for regulation development in the FinTech area. Innovative digital models offering cost savings and mediator-free solutions are rapidly taking over the financial market. This expansion requires su-

${ }^{47}$ Cf. Clause 1, Subclause 2, of the DFA Act.

${ }_{48}$ Federal Law no. 259-FZ On investments using investment platforms and amendment of certain legal acts of the Russian Federation of August 2, 2019 // SPS Consultant Plus. 
pervisory bodies to pay attention to legitimate integration and collaboration with classic institutional players. Following the introduction of new regulations, the level of trust in digital currencies and assets has risen, and new institutional players are entering the expanding crypto market. The new alliances of crypto and FinTech companies with classic market participants will allow this process to take place more efficiently.

\section{D国 References}

Allen H. (2020) Experimental Strategies for Regulating FinTech. Available at: https://papers.ssrn.com/sol3/papers.cfm?abstract_id=3533240 (accessed: 25.11.2020)

Arner D. et al (2020) Digital Finance \& the COVID-19 Crisis. University of Hong Kong. Faculty of Law. Research Paper No 2020/017. 24 p.

Arner D. et al (2016) The Evolution of FinTech: A New Post-Crisis Paradigm? University of New South Wales. Law Research Paper No. 2016-62. 45 p.

Bruno P. et al (2019) Global Payments Report 2019: Amid Sustained Growth, Accelerating Challenges Demand Bold Actions. 33 p. Available at: https://www. mckinsey.com/ /media/mckinsey/industries/financial\%20services/our\%20 insights/tracking $\% 20$ the $\% 20$ sources $\% 20$ of $\% 2$ robust $\% 20$ payments $\% 20$ growth $\% 20$ mckinsey $\% 20$ global\%20payments $\% 20$ map/global-paymentsreport-2019-amid-sustained-growth-vf.ashx (accessed: 01.12.2020)

Chen Y., Bellavitis C. (2019) Decentralized Finance: Blockchain Technology and the Quest for an Open Financial System. 27 p. Available at: https://papers.ssrn. com/sol3/papers.cfm?abstract_id=3418557 (accessed: 28.11.2020)

Fenwick M., Uytsel S., Ying B. (eds.) (2020). Regulating FinTech in Asia: Global Context, Local Perspectives. Cham: Springer, $225 \mathrm{pp}$.

Hockett R. (2020) The Treasury Dollar: An Immediate Funding and Digital Banking Plan for Pandemic Relief and Beyond. Cornell Legal Studies Research Paper No. 20-30, pp. 1-8.

Kakushadze Z., Liew J. (2018) CryptoRuble: From Russia with Love. World Economics, issue 4, pp. 165-187.

Panzarino H., Hatami A. (2020) Reinventing Banking and Finance: Frameworks to Navigate Global Fintech Innovation. L.: Kogan and Page, 250 pp.

Pollari I., Ruddenklau A. et al (2020) Pulse of FinTech H2 2019. Available at: https://home.kpmg/xx/en/home/campaigns/2020/02/pulse-of-fintech-h219-top-10-predictions-for-2020.html (accessed: 25.11.2020)

Savelyev A. (2016) Contract Law 2.0: Smart contracts as the beginning of the end of classic contract law. HSE Working Papers WP BRP 71/LAW/2016, 24 p. 
Szabo N. (1994) Smart Contracts. Available at: http://www.fon.hum.uva.nl/ rob/Courses/InformationInSpeech/CDROM/Literature/LOTwinterschool2006/ szabo.best.vwh.net/smart.contracts.html (accessed: 03.12.2020)

Ward M. et al (2020) Blockchain and cryptocurrency regulation 2020. Available at:https://www.careyolsen.com/sites/default/files/CO_Blockchain-andCryptocurrency-Regulation-2020-2nd-Edition.pdf (accessed: 27.11.2020)

Zetzsche D., Arner D., Buckley R. (2020) Decentralized Finance. Journal of Financial Regulation, issue 2, pp. 172-203.

Yankovsky R.M. (2020) Cryptocurrency in Russian Law: surrogates, other assets and digital currency. Legal Issues in the Digital Age, no 1, pp. 3-31. 